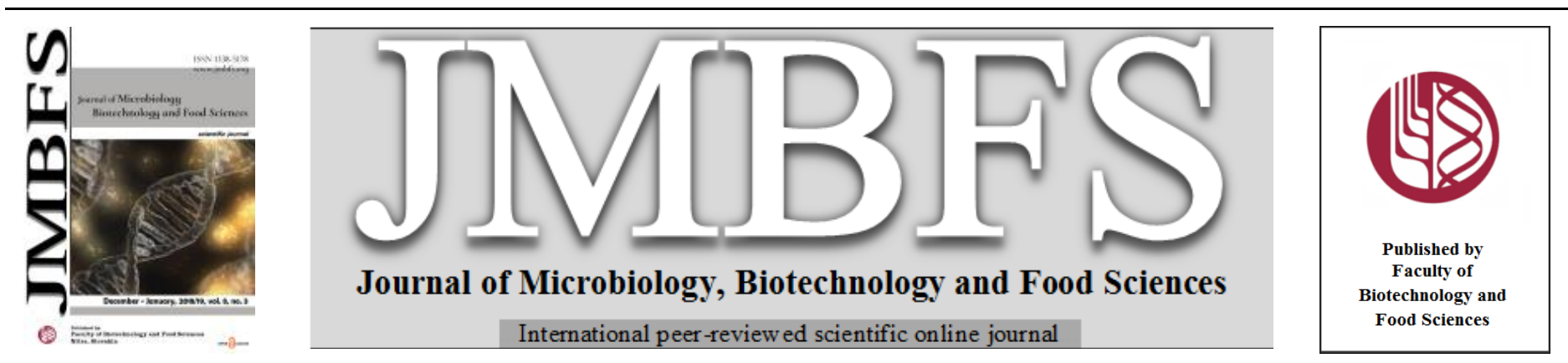

\title{
EVALUATION OF PROBIOTIC CANDIDATE IN COMBINATIONWITH TUBER EXTRACTS FROM CORALLOCARPUS EPIGAEUS (ARN.)CL. FORASSESSMENT OF IN VITRO ALPHA AMYLASE INHIBITION ACTIVITY
}

\section{Bhumika R. Gehloth and Kalpesh B. Ishnava*}

Address(es): Dr. Kalpesh B Ishnava

Ashok \& Rita Patel Institute of Integrated Study \& Reasearch in Biotechnology and Allied Sciences (ARIBAS), New Vallabh Vidyanagar - 388121, Gujarat, India.

*Corresponding author: ishnavakb203@yahoo.com

doi: 10.15414/jmbfs.2018-19.8.3.863-866

ARTICLE INFO

Received 8. 3. 2018

Revised 19. 9. 2018

Accepted 20.9. 2018

Published 1. 12. 2018

Regular article open $\odot$ access

\section{ABSTRACT}

Probiotics are living microbial adjunct which has a beneficial effect on host. Plant extracts such as those from Corralocarpus epigaeus often shows antimicrobial effect. Thus, there is always confusion about the using of herbal medicine or plant extractsinco-administration with probiotics supplement. The aim of the study was to show the synergistic action of probiotic bacteria in combination with plant extract from Coralocarpus epigaeus on alpha amylase inhibition activity. Alpha amylase inhibitors offer an effective strategy to lower the levels of post prandial hyperglycemia via control of starch breakdown. The probiotic bacterial culture in combination with different solvents for plant extraction viz. hexane, chloroform, ethyl acetate and methanol showing higher alpha amylase inhibitory activity compare to organic plant extract. The present study shows that the control having zone of diameter $(3 \mathrm{~cm})$ and methanolic plant extract $(2 \mathrm{~cm})$ and with Lactobacillus $(0.9 \mathrm{~cm})$ which isconsideredgood \% inhibition $(70 \%)$ compare to all organic solvent. While, the methanolic plant extract $(2 \mathrm{~cm})$ and Bifidobacterium $(1 \mathrm{~cm})$ also showed moderate \% inhibition $(66.66 \%)$ compare to all organic solvent. The results indicate that combination of plant extracts with probiotic cultures showing highest percentage of alpha amylase inhibition. This study revealed that synergistic actionis probiotic and plant extracts can be used to control post prandial hyperglycemia.

Keywords: Probiotics, Synergistic action, Corralocarpus epigaeus, Alpha amylase, Prandial hyperglycemia

\section{INTRODUCTION}

Probiotics are defined as live microorganisms which when administered in adequate amounts confer a health benefit on the host (Iannitti, 2010). One type of probiotics, Lactic acid bacteria (LAB), especially lactobacilli has been shown to promote beneficial effects in health including anti-cholesterol, antidiabetic, antipathogenic properties, and stimulation of the immune system (Nagpal et al., 2007). Lactobacilli are frequently used in products for human consumption and can be found as probiotics in infant foods, cultured milks, and various pharmaceutical preparations (Nagpal et al., 2011). Supplementing the diet with fermented dairy products or lactic acid bacteria containing dairy products has been shown to reduce serum cholesterol levels, as suggested by the results of several human and animal studies (Pereira et al., 2002). Activia $R$ is fermented milk manufactured with lactic cultures including yoghurt starter cultures (Lactobacillus bulgaricus and Streptococcus thermophilus) and a specific probiotic strain, Bifidobacterium lactis DN-173 010. Studies have recently indicated the role of Probiotics in the modulation of gut microbiota in diabetes conferring a beneficial effect (Caniand Delzenne, 2009).A number of reports confirmed experimentally and clinically that oxidative stress is involved in the pathogenesis and progression of diabetes mellitus as well as the subsequent complications (Ceriello et al., 2004). Generation of oxygen free radicals due to non-enzymatic protein glycosylation, auto-oxidation of glucose and impaired antioxidant defense enzymes are the most common consequences in diabetes (Sarkhail et al., 2010). This impaired balance of oxidants/antioxidants may lead to cellular damages, development of insulin resistance and dysfunction in a variety of enzymes, occurrence of inflammation process and lipid peroxidation (Maritim et al., 2003; Ceriello et al., 2004). Probiotic foods have been reported to repress the oxidative stress. L. acidophillus and $L$. casei attenuate oxidative stress and have antidiabetic effects (Ejtahed et al., 2012). It is reported that in experimentally induced diabetes with streptozotocin in rats, the strain $L$. case Shirota significantly decreased the blood levels of pro-inflammatory cytokine IL6 and acute-phase protein CRP, lowered the concentration of neutrophils and the risk of diabetic complications (Zarfeshani et al., 2011). As a probiotic supplements Lactobacillus plantarumDSM 15313 and L. gasseri BNR17 are studied in mice model of induced by high lipid diet obesity and diabetes, representing anti-diabetes effect by decreasing blood glucose level and improves glucose tolerance without influence of lipid and insulin levels (Andersson et al. 2010; Yun et al., 2009).

Pancreatic $\alpha$-amylase is key enzyme in the digestive system and its catalyse the starch hydrolysis and form mixture of oligosaccherides such as maltose, oligoglucans, this are then cleaved by glucosidase and degrade to glucose which is on absorption enters the blood stream, disturbance in this pathway lead to hyperglycemia or hypoglycemia. When rapidly starch degradation occurs, glucose level also increases rapidly in small intestine. The control of glucose level is important aspect for type 2 diabetes, hence control of starch degradation by enzyme such as $\alpha$ amylase and glucosidase play a key role in diabetes. These enzymes are major digestive enzyme and help in intestinal absorption (Sudha et al., 2011). Alpha amylase and glucosidase inhibitors are the potential targets in the development of lead compounds for the treatment of diabetes, inhibitors of this enzyme control starch degradation and slow the process of carbohydrate digestion result in reduction in glucose absorption and lowering serum glucose levels (Sivaraj et al, 2012). According to the world health organization, more than $70 \%$ of the world's population must use traditional medicine to satisfy their health need, more number of medicinal plants are used for the control of diabetes mellitus. Among 2500 species are in India, there are about 800 plants which have been reported to show anti-diabetic potential (Doss and Dhanabalan, 2008). Diabetes mellitus (DM) is the most common endocrine disorder in man, currently affecting over 170 million people world-wide and, potentially, over 365 million in the year 2030 (Wild et al., 2004). Type 2 DM is rapidly emerging as one of the greatest global health challenges of the 21 st century. According to International Diabetes Federation (IDF), the number of individuals with diabetes in 2011 crossed 366 million, with an estimated 4.6 million deaths each year. The Indian sub-continent has emerged as the capital of this diabetes epidemic in India $8.31 \%$ prevalence of diabetes in adult between the ages of 20-79 years (Prins and Arina, 2011).

Green tea extract in combination with probiotics significantly reduced the viable count of both pathogens at $4 \mathrm{~h}$ and by $24 \mathrm{~h}$ had completely abolished the recovery of viable $S$. aureus and $S$. pyogenes. These reductions were more significant than the reductions induced by probiotics or green tea extracts used separately. These results demonstrate the potential for combined therapy using the green tea extract 
plus probiotics on microbial infections caused by $S$. aureus and $S$. pyogenes. As probiotics and the green tea extract are derived from natural products, treatment with these agents may represent important adjuncts to, or alternatives to, conventional antibiotic therapy (Ping et al., 2008). Effect of dahi containing probiotic Lactobacillus acidophilus NCDC14 and Lactobacillus caseiNCDC19 $\sim 73 \times 10^{8} \mathrm{cfu} / \mathrm{g}$ ) on progression of streptozotocin (STZ)-induced diabetes in rats $(15 \mathrm{~g} /$ day/rat) for 28 days was investigated. Feeding of probiotic dah significantly suppressed the incremental peaks and area under the curve and delayed reduction of insulin secretion during oral glucose tolerance test more than skim milk or control dahi (Hariom et al., 2008).

Corallocarpus epigaeus (Arn.) $\mathrm{Cl}$. is monoecious, climber up to $4 \mathrm{~m}$ long with tuberous root. Stem angular-sulcate, tendrils simple, elongated, subfiliform, glabrous. Leaves sinuately 3 lobed, cordate and finely hairy on both surfaces Male peduncle 4-6 cm long, 5-15-flowered and female flowers often solitary on contracted axillary branch. Fruit ovoid or ellipsoid, beaked, glabrous, Seeds asymmetrically pyriform. The root contains a bitter principle allied to bryonin (Pandey et al., 2005). The present study was undertaken to investigate the synergistic action of medicinal plant and probiotics. A significant problem with herbal medicine is that herbs are slow acting in treating an ailment. Therefore, beneficial probiotics cultures that will synergistically blend with herbs to speed the medicinal activity of the herbs without side effects are used to treating diabetes.

\section{MATERIAL AND METHODS}

\section{Materials}

\section{Cultivation of Probiotic bacteria from commercially available product}

Probiotic sachets named Lactobacil ${ }^{\text {plus }}$ were collected from medical store Shakt Medical Store from Anand, Gujarat, India. This each sachet contains Lactobacillus acidophillus, Lactobacillus rhamnosus, Bifidobacterium longum, Bifidobacterium bifidum. These probioticbacteria were grown on specific media In that, $0.1 \mathrm{gm}$ of Lactobacil ${ }^{\text {plus }}$ powder inoculates in to $50 \mathrm{ml}$ of MRS broth, then it was placed on shaker for overnight. Next day, from grown culture loopful culture was taken and streak on MRS agar plate and Bifidoagar plate. That plate was incubated at $37^{\circ} \mathrm{C}$ for overnight or 2 days. From that plates, the loopfu colonies were inoculates in to the $10 \mathrm{ml}$ of MRS broth, and incubate it at $37^{\circ} \mathrm{C}$ for overnight. Those tubes marked as active culture of Lactobacillus and Bifidobacterium. Active cultures of probiotics were preserved in refrigerator for further use.

\section{Collection of plant material}

Corallocarpus epigaeus (Arn.) Cl. plant species tuber were selected and collected between June to July, 2015 form Viramgam village of Gujarat and surroundings of the region (Figure -1). The tubers of healthy and disease free plants were used for study. The plant specimens were identified by Dr. Kalpesh Ishnava (Plant Taxonomist) at Ashok and Rita Patel Institute of Integrated Study \& Research in Biotechnology and Allied Sciences (ARIBAS), New Vallabh Vidyanagar, Gujarat, India.

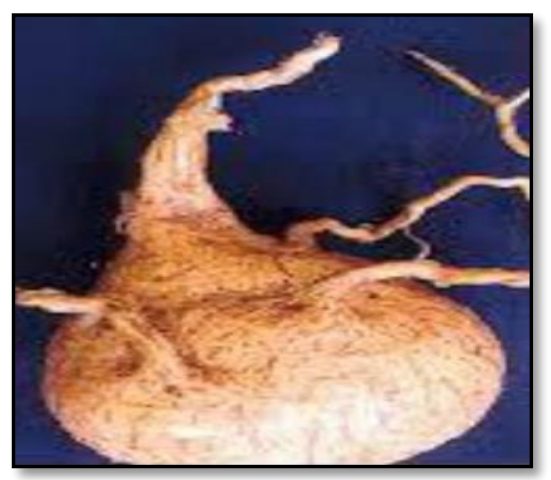

Figure 1 Corallocarpus epigaeus (Arn.) Cl. Tuber

\section{Methods}

\section{Drying and grinding the plant material}

The plant material was collected and first, the tubers were thoroughly washed under running tap water, blotted and the sample was kept drying on trays at ambient temperature and in a room with adequate ventilation (Heinrich $\boldsymbol{e t}$ al. 2004; Satyajit et al., 2006). Dry conditions are essential to prevent microbial fermentation and subsequent degradation of metabolites. Plant materials were sliced into small pieces and distributed evenly to facilitate homogeneous drying. Protection from direct sunlight is advised to minimize chemical reactions (and formation of artifacts) induced by ultraviolet rays (Satyajit et al., 2006). The dried material was stored in sealed containers in a dry and cool place. After drying, plant materials were grinded in grinder (Maharaja Mixer Ltd) into a fine powder. Grinding of plant materials into smaller particles facilitates subsequen extraction procedures by rendering the sample more homogeneous, increasing the surface area, and facilitating the penetration of solvents into cells.

\section{Preparation of plant tubers extracts}

From these, 50 grams of powdered material were soaked in $250 \mathrm{~mL}$ of hexane for 24 hours at room temperature under shaking condition (130-140 rpm). The extract was filtered with the help of Whatman filter paper number-1. The filtrate was collected in petridish and dried at room temperature. The dried extract from petridish was scraped and transferred to eppendrof tube.The residual material from the funnel was dried again and re-suspended in $250 \mathrm{~mL}$ chloroform for 24 hours at room temperature under shaking condition (130-140 rpm). The extract was filtered and collected in petridish. It was dried at room temperature. Similarly, the residual materials from the funnel are preserved and re-extracted with same volume $(250 \mathrm{~mL})$ of methanol and then Ethyl acetate respectively. In both the cases, the resultant filtrate was air dried at room temperature. The dried extract from petridish was scraped and transferred. Those dried extracts were dissolved in DMSO to obtain different concentrations i.e. $10 \mu \mathrm{g} / \mathrm{ml}$ to $100 \mu \mathrm{g} / \mathrm{ml}$ from the stock solution of $10 \mathrm{mg} / \mathrm{ml}$ plant extract.

\section{Homogenization of plant extract and probiotic culture}

Probiotic culture i.e. Lactobacillus and Bifidobacterium mixed with all four plant extracts. In that, $5 \mathrm{ml}$ of Lactobacillus culture mixed with $5 \mathrm{ml}$ of all four plant extracts having concentration of $100 \mu \mathrm{g} / \mathrm{ml}$ and $5 \mathrm{ml}$ of Bifidobacterium culture mixed with $5 \mathrm{ml}$ of all four plant extracts having concentration of $100 \mu \mathrm{g} / \mathrm{ml}$. Those test tubes were incubated at $37^{\circ} \mathrm{C}$ for 3 days for proper homogenization and then tested for in vitro alpha amylase inhibition activity.

\section{In vitro alpha amylase inhibition activity}

The DMSO method described by Jiju et al., (2013) was used; starch azure (2mg) was suspended in a tube containing $0.2 \mathrm{ml}$ of $0.5 \mathrm{M}$ Tris-HCLbuffer $(\mathrm{pH}-6.9)$ containing $0.01 \mathrm{M}$ Calcium chloride (substrate). The tubes were boiled for $5 \mathrm{~min}$ and then pre-incubated at $37^{\circ} \mathrm{C}$ for $5 \mathrm{~min}$. Different concentration of plant extracts ranging from $10 \mu \mathrm{g} / \mathrm{ml}$ to $100 \mu \mathrm{g} / \mathrm{ml}$ was prepared from the stock solution $(10 \mathrm{mg} / \mathrm{ml})$. Then $0.2 \mathrm{ml}$ of plant extract of a concentration was put in the above tubes containing the substrate solution. $0.1 \mathrm{ml}$ of porcine pancreatic amylase in Tris-HCL buffer ( 2 units $/ \mathrm{ml}$ ) was added to the tube containing the plant extract and substrate solution. The process was carried out at $37^{\circ} \mathrm{C}$ for $10 \mathrm{~min}$. The reaction was stopped by adding $0.5 \mathrm{ml}$ of $50 \%$ acetic acid in each tube. The reaction mixture was then centrifuged (Eppendroff-5804 R) at $3000 \mathrm{rpm}$ for 5 min at $4^{\circ} \mathrm{C}$. The absorbance of resulting supernatant was measured at $595 \mathrm{~nm}$ using spectrophotometer.

The absorbance was calculated by following formula.

100

$\%$ amylase inhibition $=\underline{(\text { Diameter of control }- \text { Diameter of test })} \times$

\section{Alpha amylase inhibition screening assay}

Diameter of control

This assay was performed according with the method describe by Gulati $\boldsymbol{e t}$ al., (2012). A $160 \mu \mathrm{l}$ of alpha amylase enzyme solution and $120 \mu \mathrm{l}$ of plant extract mixture were mixed and incubated at $37^{\circ} \mathrm{C}$ for $45 \mathrm{~min}$. After, incubation the mixture was poured into the well made in the petriplate containing $3 \%$ agar $(\mathrm{w} / \mathrm{v})$ and $1.2 \%$ starch (w/v).Plates could stand for 3 days at $25^{\circ} \mathrm{C}$ and then flooded with iodine solution and allowed to stand for $15 \mathrm{~min}$. The diameter of zone of starch hydrolysis was measured. As a control, the enzyme was added into the well of the plate without plant extract. The \% inhibition was calculated by following equation.

$\%$ amylase inhibition $=\underline{(\text { Diameter of control-Diameter of test })} \times 100$ Diameter of control

\section{RESULT AND DISCUSSION}

In this study, the tuber extract of $C$. epigaeus was investigated. The inhibitory effect of chloroform, Methanol, Ethyl acetate and Hexane was analyzed. The percentage inhibition of alpha amylase by the extracts of $C$. epigaeus was studied in range of $10 \mu \mathrm{g} / \mathrm{ml}$ to $100 \mu \mathrm{g} / \mathrm{ml}$. The two out of four extracts, chloroform extract and methanolic extract comparatively were more effective than ethyl acetate and hexane in inhibiting alpha-amylase. Ismail Shareef et al., (2014) reported the alpha amylase inhibitory activity of the leaves of Tinospora cordifolia. They analysed four extracts petroleum ether, chloroform, ethyl acetate and methanol among them ethyl acetate and methanol showing higher alpha amylase inhibiting activity than petroleum ether and chloroform (Amulya et al. 2014). This finding suggested that some of the alpha amylase inhibitory components in $C$. epigaeus plant extract may be structural analogs of the 
substrate of alpha amylase. Following Figure 2 shows the inhibition of alpha amylase enzyme by plant extract of Corralocarpus epigaeus.

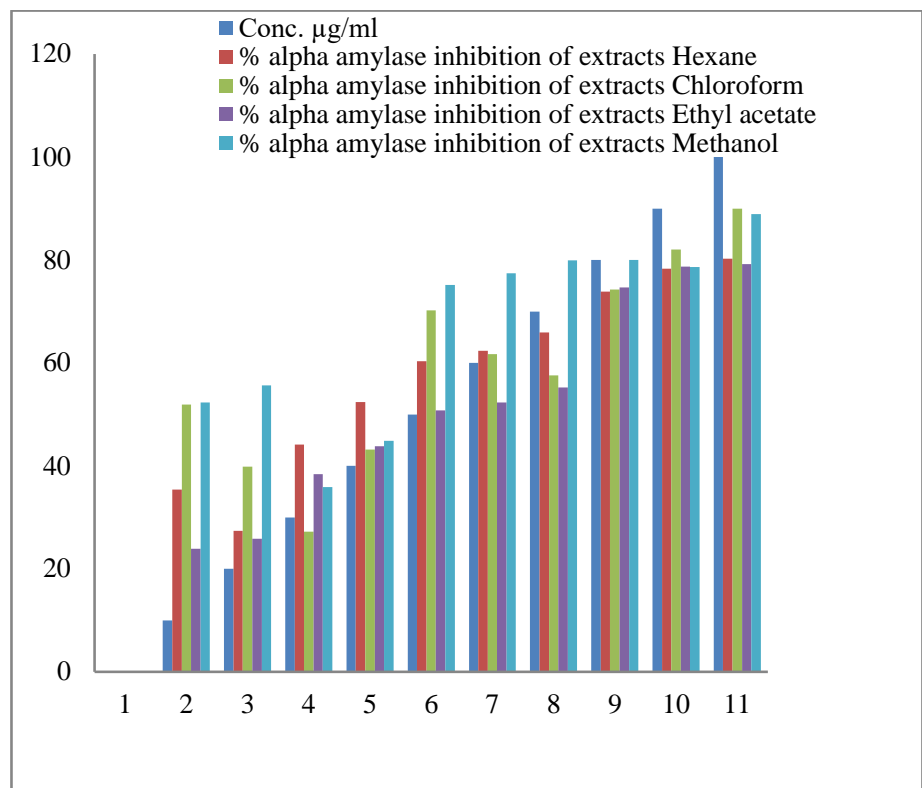

Figure 2 Inhibition of alpha amylase enzyme by different solvent plant extract

The Lactobacillus culture was homogenized with all four plant extracts and checked for its alpha amylase inhibition activity (Figure 3). Plant extracts while homogenized with probiotic culture give synergistic action. So, ultimately it may improve the speed of herbal medicines which we are using for treating diseases. The following Figure 3 showing the inhibition of alpha amylase enzyme by combination of plant extracts with Lactobacillus culture.

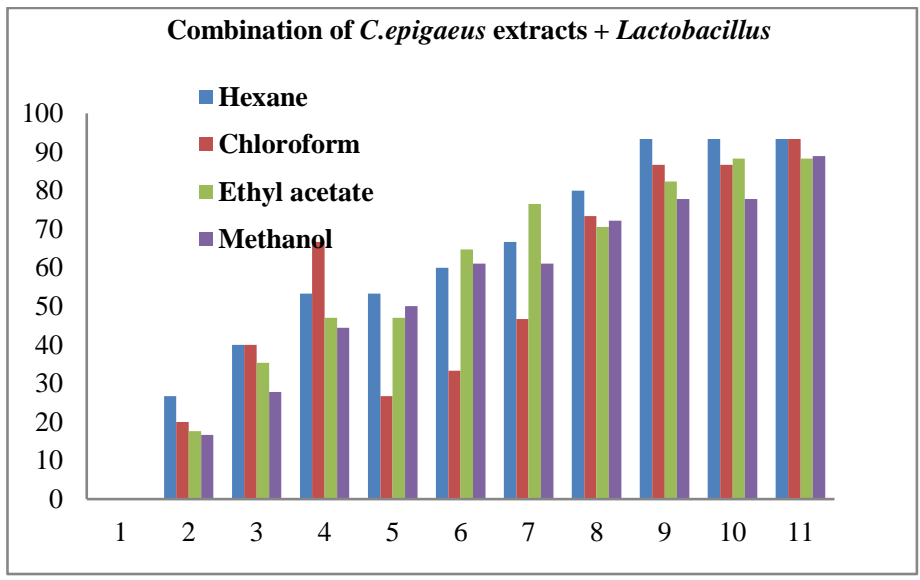

Figure 3 Inhibition of alpha amylase enzyme by combination of plant extracts with Lactobacillus culture

According to above results, Lactobacillus culture in combination with Hexane and chloroform extract of $C$. epigaeus gave large percentage of alpha amylase inhibition at concentration of $00 \mu \mathrm{g} / \mathrm{ml}$. The ethyl acetate and methanolic extract with Lactobacillus culture also showing moderate percentage alpha amylase inhibition compare to four extracts of $C$. epigaeus tuber. Shori et al., (2013) reported that maximum inhibition of alpha amylase $(47.4 \pm 5.8 \%)$ and alpha glucosidase $(15.2 \pm 2.5 \%)$ by plain yogurt water extract occurred on day 7 and 14 respectively. Azadirachta indica yogurt water extract increased the inhibition to maximal on 14 day and 21-day storage i.e. $15.9 \pm 10.1 \%$ and $54.8 \pm 3.2 \%$ respectively. A. indica yogurt has higher inhibitory effects than plain yogurt. Treatment with probiotics has been suggested to have a potent effect in type 2 diabetes by improving the endogenous flora as previous studies suggest that modulating gut microbiota could be beneficial for improving glycemic control (Cani and Delzenne, 2009). Al-Salami et al., (2008) have shown that probiotic treatment of diabetic rats given gliclazide, increased its bioavailability and lowered blood glucose levels by insulin-independent mechanisms, suggesting that the administration of probiotics may be beneficial as adjunct therapy in the treatment of diabetes. Thus, probiotic bacteria with plant extracts may have the potential to serve as enhanced anti-diabetic activities (Shori et al., 2013). The Bifidobacterium culture was homogenized with all four plant extracts and checked for its alpha amylase inhibition activityby DMSO method. The following Figure 4 showing the alpha amylase inhibition by combination of plant extracts with Bifidobacterium culture $100 \mu \mathrm{g} / \mathrm{ml}$.

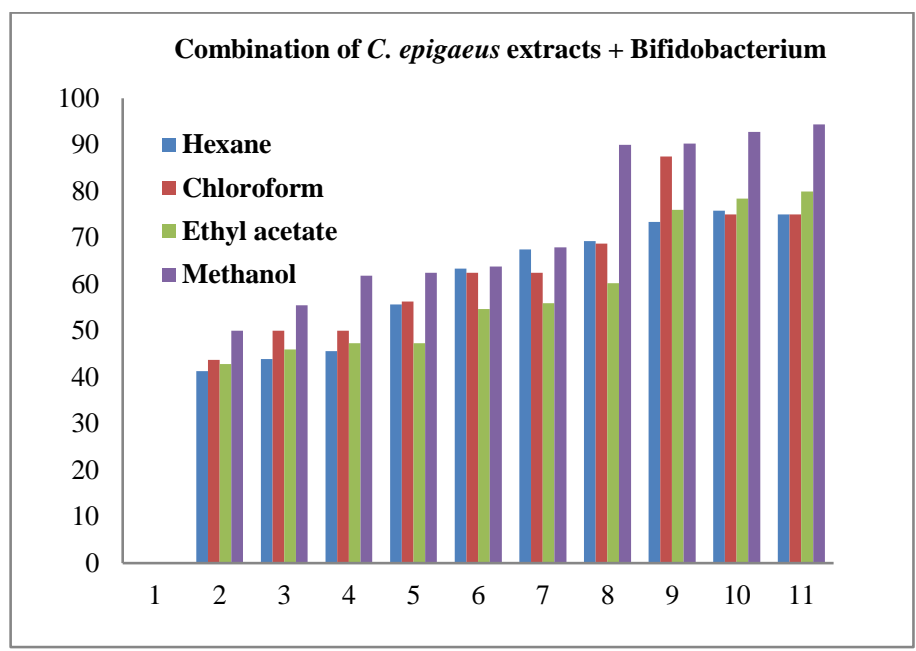

Figure 4 Effect of concentration on the inhibition of alpha amylase enzyme by combination of plant extracts with Bifidobacterium culture

According to above results, Bifidobacterium culture in combination with ethyl acetate and methanol extract of $C$. epigaeus gave large percentage of alpha amylase inhibition at concentration of $100 \mu \mathrm{g} / \mathrm{ml}$ (Figure 5). The Hexane and chloroform extract with Bifidobacterium culture also showing moderate percentage alpha amylase inhibition compare to four extracts of $C$. epigaeus tuber. Kattamanchi et al., (2013) reported the ethanolic extract of Corallocarpus epigaeus rhizomes possesses the antidiabetic action which is comparable with that of the standard Glibenclamide drug employed. The combination of the probiotic bacteria with plant extracts having comparatively good antidabitic activity compare to the only use of the plant extract. Marhamatizade (2015) reported the garlic extract increased dill concentration in probiotic Bifidobacterium bifidum yoghurt was negatively correlated with reduced serum Triglycerides in the rats $(0.6 \%<0.4 \%<0.2 \%)$, and the $0.2 \%$ concentration had the greatest effect, even more than the control sample. Bifidobacterium bifidum yoghurt with dill extract was found to be more effective in reducing serum cholesterol in rats. The increased garlic concentration in Bifidobacterium bifidum yoghurt was positively correlated with reduced serum cholesterol $(0.2<0.1<0.3 \%)$. The Bifidobacterium bifidum yoghurt with garlic extract was found to be more effective in reducing serum cholesterol in rats. Treatment with probiotics has been suggested to have a potent effect in type 2 diabetes by improving the endogenous flora as previous studies suggest that modulating gut microbiota could be beneficial for improving glycemic control (Cani and Delzenne, 2009). Thus, probiotic bacteria with plant extracts may have the potential to serve as enhanced anti-diabetic activities (Shori et al., 2013).

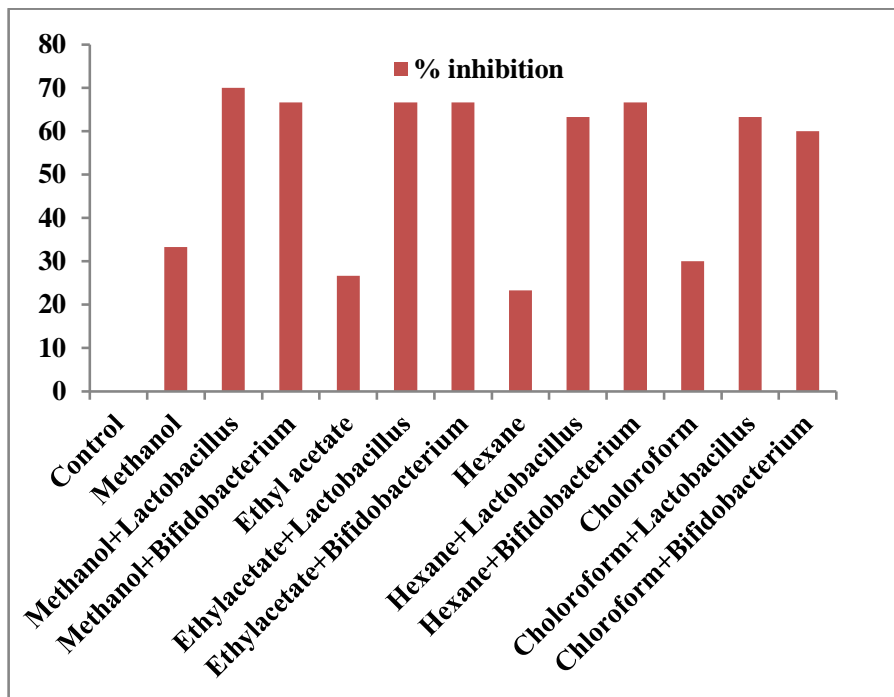

Figure $5 \%$ alpha amylase inhibition by screening assay

The inhibition of digestive enzymes, such as $\alpha$-amylase and $\alpha$-glucosidase has been an effective strategy to control blood glucose. Agents based on natura products are particularly attractive as side effects are minimal and the therapies are well-tolerated compared to the other oral hypoglycemic agents currently available. 
The present study shows that the control having zone of diameter $(3 \mathrm{~cm})$ (Figure 6A) and methanolic plant extract $(2 \mathrm{~cm})$ (Figure 6B) and with Lactobacillus $(0.9 \mathrm{~cm})$ (Figure 6C) which is good \% inhibition $(70 \%)$ compare to all organic solvent. While, the methanolic plant extract $(2 \mathrm{~cm})$ (Figure 6B) and with Bifidobacterium $(1 \mathrm{~cm})$ (Figure 6D) also showed moderate \% inhibition $(66.66 \%)$ compare to all organic solvent.
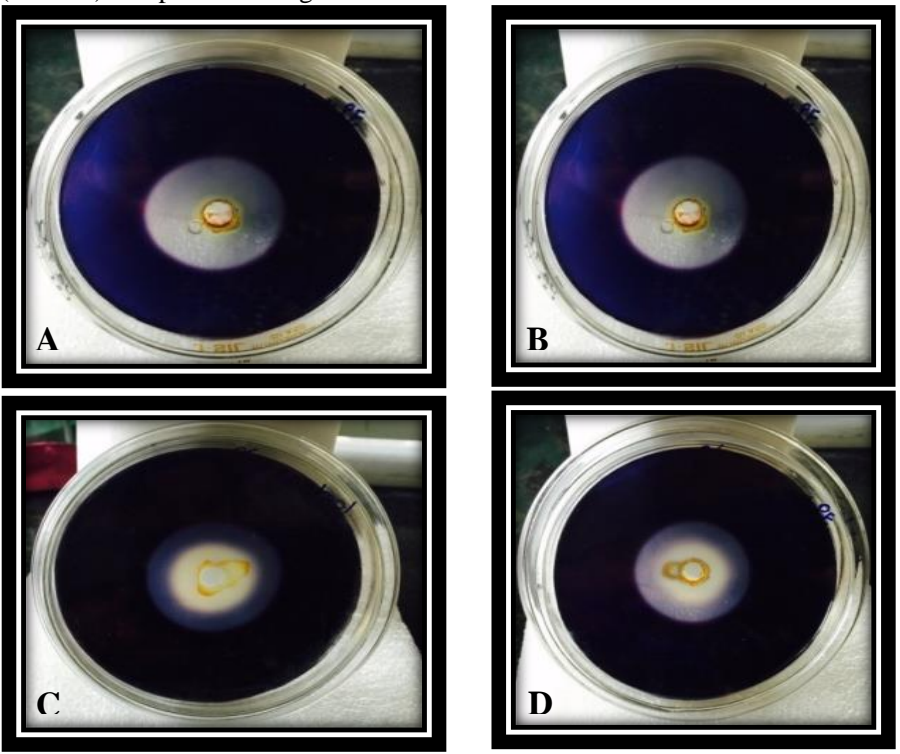

Figure 6 (A) control (B) Methanolic extract (C) Methanolic extract + Lactobacillus (D) Methanolic extract + Bifidobacterium

This indicates that combination of plant extracts with probiotic cultures showing highest percentage of alpha amylase inhibition. So, the combination can be applied for the treatment of post prandial hyperglycemia. Gulati et al., (2009) reported from the results of preliminary agar diffusion amylase inhibition assays indicated that all the Australian aboriginal plant extracts showed complete inhibition of $\alpha$-amylase enzyme such that no hydrolysis of starch was evident (Gulati et al., 2009).

\section{CONCLUSION}

Probiotics and plant extract both have a great potential in terms of their beneficial effect. They show synergistic action on $\alpha$-amylase inhibition. Probiotic in combination with plant extract exhibit potent $\alpha$-amylase inhibitory activity and this therapeutic potentiality could be exploited in the management of post prandial Hyperglycemia. However, much reasearch is needed to be put into these studies for cytotoxicity and drug doses.

Acknowledgments: Authors are thankful to Charutar Vidya Mandal, Vallabh Vidyanagar and Director of ARIBAS, New Vallabh Vidyanagar, Gujarat, India for providing necessary support for research and laboratory facility.

\section{REFERENCES}

Iannitti, T., Palmieri, B. (2010). Therapeutical use of probiotic formulations in $\begin{array}{llll}\text { clinical } & \text { Clinical } & \text { Nutr, } & 29(6), 701-25\end{array}$ http://dx.doi.org/10.1016/j.clnu.2010.05.004

Nagpal, R., Behare, P.V., Kumar, M.(2011). Milk, milk products and disease free health: An updated overview. Crit Rev Food Sci and Nutr,52(4),15492.http://dx.doi.org/10.1080/10408398.2010.500231

Nagpal, R., Yadav, H., Puniya, A.K., Singh, K., Jainm, S., Marotta, F. (2007). Potential of probiotics and prebiotics for symbiotic functional dairy foods. Int $J$ Probiotics and Prebiotics, 2,75-84.

Pereira, D., Gibson, G.R. (2002). Effects of consumption of probiotics and prebiotics on serum lipid levels in humans. Critical Review of Biochemistry and Molecular http://dx.doi.org/10.1080/10409230290771519

Cani, P.D., Delzenne, N.M. (2009). The role of the gut microbiota in energy metabolism and metabolic disease. Curr Pharm Des, 15(13), 1546-58.

Ceriello, A., Motz, E. (2004). Is oxidative stress the pathogenic mechanism underlying insulin resistance, diabetes, and cardiovascular disease? The common soil hypothesis revisited. Arterioscler Thromb Vasc Biol, 24,816-823

http://dx.doi.org/10.1161/01.ATV.0000122852.22604.78

Sarkhail, P., Abdollahi, M., Fadayevatan, S., Shafiee, A., Mohammadirad, A. Dehghan, G., Esmaily, H., Amin, G. (2010). Effect of Phlomis persica on glucose levels and hepatic enzymatic antioxidants in streptozotocin induced diabetic rats. Pharmacogn Mag, 6, 219-224.http://dx.doi.org/2011/7/25/40/75900
Maritim, A.C., Sanders, R.A., Watkins, J.B. (2003). Diabetes, oxidative stress, and antioxidants: a review. $J$ Biochem Mol Toxicol, 17,24-38. http://dx.doi.org/10.1002/jbt.10058

Ejtahed, H.S., Mohtadi-Nia, J., Homayouni-Rad, A., Niafar, M., AsghariJafarabadi, M., Mofid, V. (2012). Probiotic yogurt improves antioxidant status in type 2 diabetic patients. Nutrition, 28,539-543. http://dx.doi.org/:10.1016/i.nut.2011.08.013

Zarfeshani, A., Khaza'ai, H., Mohd, A.R., Hambali, Z., Wahle, K.W.J., Mutalib, M.S.A. (2011). Effect of Lactobacillus casei on the production of proinflammatory markers in streptozotocin-induced diabetic rats. Probiotics \& Antimicro Prot, 3(3),168-174. http://dx.doi.org/10.1007/s12602-011-9080-9

Yun, S.I., Park, H.O., Kang, J.H.(2009). Effect of Lactobacillus gasseri BNR17 on blood glucose levels and body weight in a mouse model of type 2 diabetes. $J$ Appl Microbiol,107,1681-1686. http://dx.doi.org/:10.1111/j.1365672.2009.04350.x

Andreasen, A.S., Larsen, N., Pedersen, S.T., Berg, R.M., Moller, K., Svendsen, K.D., Jakobsen, M., Pedersen, B.K. (2010). Effects of Lactobacillus acidophilus NCFM on insulin sensitivity and the systemic inflammatory response in human $\begin{array}{lllll}\text { subjects. } & \mathrm{Br} & \mathrm{J} & \mathrm{Nutr}, & 104,1831-1838\end{array}$ http://dx.doi.org/10.1017/S0007114510002874

Sudha, P., Zinjarde, S.S., Bhargava, S.Y., Kumar, A.R. (2011). Potent a -amylase inhibitory activity of Indian ayurvedic medicinal plants. Complementary and Alternative Medicine

11(1),5.

http://dx.doi.org/10.19080/JCMAH.2018.07.5557/18

Sivaraj, A., Preethi, J., Kavitha, M., Inbasekar, P., Senthilkumar, B., Panneerselvam, A.(2011). Antibacterial Activity of Coccinia grandis leaf extract on selective bacterial strains. Journal of Pharmaceutical Science, 1(7), 120-23.

Doss, A., Dhanabalan, R. (2008). Anti-hyperglycaemic and insulin release effects of Coccinia grandis (L.) Voigt Leaves in normal and alloxan diabetic rats. Ethnobotanical Leaflets, 12,1172-75. http://dx.doi.org/10.7324/JAPS.2013.3522 Wild, S., Roglic, G., Green, A., Sicree, R., King, H. (2004). Global prevalence of diabetes: estimates for the year 2000 and projections for 2030.Diabetes Care, 27:1047-53.https://doi.org/10.2337/diacare. 27.5. 1047

Prins, Arina. (2011). Probiotics: 'Conbiotics' or medicine of the $21^{\text {st }}$ century? South African Journal of Clinical Nutrition, 24(2),59-60. http://dx.doi.org/10520/EJC65240

Ping, Su., Anders, H., Christina, N., Hazel, M. (2008). Synergistic effect of green tea extract and probiotics on the pathogenic bacteria, Staphylococcus aureus and Streptococcu spyogenes. World Journal of Microbiology and Biotechnology, (24)9,1837-1842. https://doi.org/10.1007/s11274-008-9682-x

Hariom, Y., Shalini, J., Pushpalata, R.S. (2008). Oral administration of dahi containing probiotic Lactobacillus acidophilus and Lactobacillus casei delayed the progression of streptozotocin -induced diabetes in rats. Journal of Diary Research, 75 (2),189-195. http://dx.doi.org/10.1017/S0022029908003129

Heinrich, M., Barnes, J., Gibbons, S., Williamson, E.M. (2004). Fundamentals of Pharmacognosy and Phytotherapy. Churchill Livingstone, Elsevier Science Ltd. UK.

http://dx.doi.org/10.1590/S1516-93322004000300027

Satyajit, D., Sarker, Z., Latif, A., Gray, I. (2006). Natural product isolation. Second edition, Humana Press Inc ISBN 1-59259-955-9. https://doi.org/10.1021/np078142v

Jiju,V., Charly, S., Neemu, S.T., Mridhula, M., Deepa, T., Vasudevan. (2013). The inhibitory effect of Carica papaya leaf extracts on alpha amylase. Universal Journal of Pharmacy, 2(1),135-139.

Gulati, A.,Vyas, P., Rahi, P., Kasana, R.C.(2009).Plant growth promoting and rhizosphere competent Acinetobacter rhizosphere strain BIHB 723 from the cold desert of Himalayas. Curr Microbiol, 58, 371-377. http://dx.doi.org/10.1007/s00284-008-9339-x

Amulya,G., Sudharani,R., Ismail Shareef, M., Gopinath, S.M.(2014).Haemato Biochemical changes in sheep suffering from gastrointestinal parasitism. Indian J Field Vets, 10 (2),20-22

Shori, A.B., Baba, A.S. (2013). Effects of incusion of Allium Sativum and Cinnamomum Verum in milk on the growth and activity of lactic acid bacteria during yogurt fermentation. AmericanEurasian Journal of Agricultural Environ Sci,13(11),1448-1457. http://dx.doi.org/ 10.5829/idosi.aejaes.2013.13.11.76177 Al-Salami, H., Butt, G., Fawcett, J.P., Tucker, I.G., Golocorbin-Kon, S., Mikov M.(2008). Probiotic treatment reduces blood glucose levels and increases systemic absorption of gliclazide in diabetic rats. Eur Journal Drug Metabolism Pharmacokinet, 33(2),101-6. http://dx.doi.org/PMID:18777945

Kattamanchi, G., Kontham, R., Gudur, P.K., Bheemanapally Krishna, R., Avvari Sanjeeva ,Kumar. (2013). Evaluation of antidiabetic activity in Corallocarpus epigaeus rhizomes. International Current PharmaceuticalJournal,2(3),5356.http://dx.doi.org/10.3329/icpj.v23

13581

Marhamatizade, M.H.(2015). Effect of garlic and dill extract on yoghurt probiotic bacteria (Bifidobacterium bifidsum and Lactobacillus acidophilus) and their role in rat's triglycerides and cholesterol. Bull Env Pharmacol Life Sci, 4(3),1 